\title{
PREDICTION OF PROGNOSIS IN PATIENTS OF DIFFUSE BRAIN INJURY USING PROGNOSTIC PREDICTIVE MODEL DEVELOPED BY NIMHANS
}

Devendra Singh Dhaker, Yogendra Singh Bhakuni, Ashish Kumar Dwivedi, A. K. Chaurasia, M. C. Songra

1. Senior Resident. Department of Surgery, Gandhi Medical College. Bhopal.

2. Junior Resident. Department of Surgery, Gandhi Medical College. Bhopal.

3. Senior Resident. Department of Surgery, Gandhi Medical College. Bhopal.

4. Assistant Professor. Department of Surgery, Gandhi Medical College. Bhopal.

5. Professor. Department of Surgery, Gandhi Medical College. Bhopal.

\section{CORRESPONDING AUTHOR:}

Devendra Singh Dhaker,

House No.30, Sector 4,

Global Park City, Katara Hill Bhopal,

Pincode - 462043.

E-mail: dr.devendradhakad@yahoo.com

BACKGROUND: The management part of patients of diffuse brain injury is always critical and is associated with the high mortality and morbidity. Many prediction model for prognosis evaluation in diffuse brain injury patients have been developed. These prediction models so far has shown no promising role in therapeutic part of management but sensitivity and specificity of such model in detecting outcome has been observed and validated. In our study we have compiled the data of 400 patients with diagnosis of diffuse brain injury and evaluated their predicted outcome based on prediction scoring developed by National Institute of Mental Health and Neurosciences (NIMHANS) in 2003 and observed the actual outcome at the end of one month of observation. MATERIAL \&METHODS: The outcomes of 400 patients with severe diffuse brain injury $(\mathrm{GCS}<8)$ were analyzed prospectively. On admission their prediction scoring were done based on the NIMHANS prognostic predictive model .Patients with scores of less than zero were graded to have unfavourable outcome. The actual outcomes of the patients at the end of one month were observed - death or persistent vegetative state was grouped in unfavourable outcome whereas patients those who showed improvement with or without disability were said to have favourable outcome. The percentage of unfavourable outcome was measured and the sensitivity, specificity. Predictive value for favourable and unfavourable outcome of the model in our study was measured and compared to the original study of NIMHANS. RESULTS: The sensitivity, specificity, negative and positive predictive value for the model calculated were 71.68, 83.33, 53. 98 and 91.52 respectively which showed the good efficacy of the model in predicting the outcome in our patients of head injury. CONCLUSION: The prognostic model developed by NIMHANS is a good outcome prediction model which can guide towards the prognosis and further intensive care of the patient but at the same time cannot be used to guide initial therapy .Moreover inclusion of MRI findings can improve accuracy of the study as CT Scan may not show obvious changes in thin patient.

INTRODUCTION: Head injury is a significant economic social \& medical problem in India. Among the Road Traffic Accidents 70\% have head injury. Majority of death occurs during first 72 hours. For this reason prognostic factors in head injury are of major importance to all surgeons who treat severely injured patients. Maximum Incidence of head injury is found in 30s 
\& 40s of life. prognosis become poorer as the age rises .In severe head injury the patient may have loss of consciousness, vomiting, seizures inability to awaken, dilatation of one or both pupils and neurological deficit, all together are important indicator of prognosis among all TBI(Traumatic Brain Injury) many patient admitted with severe diffuse head injury. The management of diffuse brain injury (DBI) patients demands the dedication of expensive and limited intensive care resources for considerable lengths of time. The optimal use of such resources is possible if we can predict at admission which patients are unlikely to improve. In past and recent studies has developed many outcome predictive models in diffuse brain injuries considering many factors individually or in combination include Glasgow Coma Scale Score (GCS), $1,3,4,6,14$ Pupillary Reactivity, $, 4,4,6,14$ early hypoxia and hypotension, $, 1,5,8,14$ Brain stem reflexes, ${ }^{1,6,7,9,14}$ and CT(Computed Tomography) findings.5,10,11,14However, in spite of using various combinations of predictors no model has satisfied all the requirements of an ideal model. Retrospective analysis was conducted in order to evolve a model to predict the outcome in a patient with Severe Diffuse Brain Injury in the emergency room and test its efficacy by prospectively in a different set of patients by NIMHANS (National Institute of Mental Health and Neurosciences) in 2003. Our study is based on the prediction model developed by NIMHANS for evaluation the efficacy of model in 400 patients admitted in a surgical unit of Tertiary Care Centre with severe diffuse brain injury in 4 years period.

PATIENTS AND METHODS: This Study is based on the prospective analysis of 400 patients admitted in a surgical unit, Tertiary Care Centre between 2009 -2013with post resuscitation $\mathrm{GCS}^{12}$ of 8 or less with CT Scan Head finding suggestive of diffuse brain injury. Patients were divided in age group of less than 45 years and more than 45 years. Patient with midline shift due to asymmetric hemispheric oedema or with minor tissue tear haemorrhagic were also included in the study. Patients who were considered operable (midline shift $>5 \mathrm{~mm}$ and a significant mass effect with hematoma and contusion) were excluded from the study. Also the patients with injury to other organs, brain dead at the time of admission or those who did not survive for more than 24 hours and those without records of outcome at 1 month or lost follow up were excluded from the study.All Patients examined in detail and sign of patients were recorded meticulously. All included patients of severe head injury on admission were clinically managed with anti-oedema measures. They were mechanically ventilated in the presence of respiratory embarrassment or if CT scan showed evidence of severe diffuse oedema with or without midline shift. . The data from the patient were incorporated in the prediction score developed by the NIMHANS. ${ }^{14}$

Prediction Score $=(3 \times$ OCR $)+(0.5 \times$ MGCS $)-(M S)-6.6$

Where, OCR - Oculocephalic Reflex; MGCS - Motor Score Of GCS ; MS - Midline shift on CT Scan Head.

Factors were coded as follow -

Oculocephalic Reflex - absent - 1; Present - 2

Motor Score of GCS - 1 to 5

Midline Shift - Absent - 1; $<5 \mathrm{~mm}-2 ;>5 \mathrm{~mm}-3$

If the value of the prediction score is less than zero then the outcome is likely to be unfavourable. ${ }^{14}$

NIMHANS prediction model ${ }^{14}$ predicted outcome was calculated and the predicted outcome of these patients was compared to the actual outcome at 1 month . The patient who 
improved with or without some disability were said to have favourable outcome at one month where as those still in vegetative state or died were said to have unfavourable outcome.

RESULTS \& OBSERVATION : The present study was conducted in a Surgical Unit of Tertiary Care Centre and 400 patients were observed from (January 2009 to January 2013). In our study we observed more number of younger patient $(<45$ years; $n=284)$ as compared to elder population ( $>45$ years ; $\mathrm{n}=116$ ), with more percentage of unfavourable outcomes seen in the age group( $>45$ years) as compared to age group of $<45$ years ( $88 \%$ vs. $70 \%$; Table 1 ) at the end of 1 month and it was observed that the mortality increases with increasing age. The factors to incorporate in NIMHANS prediction score ${ }^{14}$ were observed and calculated for predicting outcome in our patient at the end of 1 month. In our study, 172 patient presented with negative oculocephalic reflex and when they were included in model ${ }^{14} 164$ patients were predicted to have unfavourable outcome and on observation 154 patient had unfavourable outcome $(93.902$ $\%$; Table 2) and on other side 228 patient presented with positive oculocephalic reflex and on including these patient model ${ }^{14} 122$ patients were predicted to have unfavourable outcome and on observation 62 patients shown unfavourable outcome at the end of 1 month $(50.82 \%$; Table 2 ) .It was observed that negative oculocephalic reflex has prognostic significance in our study.In our study when Motor score was observed as a prognostic factor, 100 patients with motor score 1 (M -1) were put into the Prediction formula14 94 patient were predicted to have unfavourable outcome out of which 89 patients presented with unfavourable outcome at the end of 1 month (94.681\%; Table 3) and with the increasing motor score unfavourable outcome percentage decreased ( Table 3) showing prognostic significance of motor score of GCS in head injury patient.In Our Study 228 patient presented with the no midline shift and on including them in model 170 patient were predicted to have adverse outcome and at the end of one month 115 patient shown poor outcome $(67.647 \%$, Table 4$)$ and out of 106 patient with midline shift of less than $5 \mathrm{~mm}$ in which 94 were predicted to have poor outcome of which 81 shown poor outcome at the end of 1 month $(86.17 \%$, Table 4$)$, remaining 66 patient with midline shift of $>5$ mm 60 were predicted to have poor outcome and 57 of them ( $95 \%$, Table 4) shown adverse outcome at the end of one month. The Data were evaluated and charted to calculate and make a comparison between the outcome in the patient of head injury on basis of prediction score developed by NIMHANS ${ }^{14}$ and final outcome seen at the end of 1 month (Table 5 and 6) .The sensitivity, specificity, negative and positive predictive value for the model was calculated by keeping patients with unfavourable outcome and with NIMHANS prediction score of less than zero as true positive cases and it was calculated as 71.68, 83.33, 53.98 and 91.52 respectively.(Table 7)

DISCUSSION : Our study was based on Prognosis prediction model of NIMHANS ${ }^{14}$ for evaluation the efficacy of model in our patients. In our study it was observed in 400 patients the majority of the patients were young adult males-the mean age of patients who had an unfavorable outcome was $35 \pm 10$ years while that of patients who had a favorable outcome was $23 \pm 12$ years and this difference was significant ( $\mathrm{t}$-test, $\mathrm{P}=0.01$ ). Almost all the patients older than 45 years $(88 \%)$ had an unfavorable outcome as compared to those younger except for those younger than 10 years The age of the patient influences both the likelihood of Traumatic Brain Injury and the prognosis. TBI has a bimodal incidence distribution; young adult males comprise the largest peak because of motor vehicle accidents and alcohol-associated trauma with a second smaller peak in the elderly, consequent to falls. Increasing age, especially beyond 40-55 years, has been 
included as a valuable factor in several prediction models.1,2,4,5,14,17,18. In children age is not seen as major predictor of outcome.14,15,16

The GCS, pupillary reaction and/or oculocephalic reflex form a part of most prediction models in both adults and children. $14,4,6,7,9,15,16,17,18$ As in NIMHANS study ${ }^{14}$ the GCS sum score as well as the individual scores were evaluated as outcome predictors and they observed that the GCS sum score, the motor score and the verbal response score were all highly significant predictors of poor outcome. When we distribute patients in two group according to oculocephalic reflex, $92.073 \%$ of the patients with absent Oculocephalic reflex were found to have a poor outcome. This is similar to the study of NIMHANS 14 in which $98.40 \% 40$ of the patients with absent pupillary light reflex were found to have a poor outcome. In past study on prognostic factors for severe head injury 20 showed negative oculocephalic reflex has unfavourable outcome in head injury patient and in original study of NIMHANS ${ }^{14}$ prognostic significance of negative oculocephalic reflex was observed and thus was incorporated in prediction model which we used.

Finally in our study the prediction score of the outcome calculated, by using NIMHANS Model $^{14}$ and compared with actual outcome observed and predictive value for both favourable and unfavourable outcome were compared, predictive value for unfavourable outcome (specificity) was 83.33 and for favourable outcome (sensitivity) was 71.68 as compared to the NIMHANS model 86 and 50 respectively. ${ }^{14}$ The sensitivity, specificity, negative and positive predictive value for the model calculated were $71.68,83.33,53.98$ and 91.52 respectively which showed the good efficacy of the model in predicting the outcome.

NIMHANS study has highlighted the fact that both clinical and CT scan findings are important in the prediction of outcome following severe diffuse brain injury. The factors which were found to have a significant bearing on the outcome at 1 month included GCS, pupillary reaction, oculocephalic reflex, and CT scan findings of effacement of ventricles and basal cisterns, presence of SAH (Sub Arachnoid Haemorrhage) and midline shift. Three of these, namely, oculocephalic reflex, motor score of GCS and the extent of midline shift on CT scan were found to be the important predictors and could be combined to develop a simple outcome prediction model. This fact was found in our study also.

The chief advantage of the NIMHANS model is good sensitivity combined with ease of calculation using only 3 factors. Like the Narayan Logistic model ${ }^{19}$, this model cannot be used to make a decision regarding withdrawal of treatment because its rate of false pessimistic results is $33 \%$. NIMHANS study therefore is in agreement with Waxman etal ${ }^{5}$ that prediction models cannot be used to decide on the initial course of treatment for a particular patient. In the Indian context, a similar model, though using clinical variables alone, was developed in a pilot study by Mukherjee et al. ${ }^{13}$ They too concluded that "the calculated prediction should not cloud clinical judgment". The chief utility of efficient models like Narayan Logistic model ${ }^{19}$ and the NIMHANS model ${ }^{14}$ would be in the rational utilization of limited resources and during counselling of the relatives of patients.

CONCLUSIONS: The management part of head injury is always critical and is associated with high rates of mortality and morbidity. The use of outcome prediction model like NIMHANS in management of the head injury patient is rationalized with the help in division of patient with adverse and better outcome but the initial therapy cannot be based on such models due to high pessimistic values. In future studies and research we can come up with such models with incorporation of more factors apart from CT finding, Motor finding of GCS and Oculocephalic 
reflex with the upcoming minimal invasive technologies that would able to work on the management of head injury patient in better way.

LIMITATIONS OF STUDY: In our study intracranial pressure changes are assessed by clinical signs i.e. anisocoria, bradycardia, and hypertension. For better evaluation invasive intracranial pressure monitoring is needed. As this study includes mainly patients with severe diffuse brain injury, CT Scan may not show obvious changes in these patients. With the use of MRI(Magnetic Resonance Imaging) accuracy of the study can be further improved.

\section{REFERENCES:}

1. Choi SC, Narayan RK, Anderson RL, Ward JD. Enhanced specificity of prognosis in severe head injury. J Neurosurg 1988;69:381-5.

2. Hans P, Albert A, Born JD, Chapelle JP. Derivation of a bioclinical prognostic index in severe head injury. Intensive Care Med 1985;11:186-91.

3. Ratanalert S, Chompikul J, Hirunpat S, Pheunpathom N. Prognosis of severe head injury: an experience in Thailand. Br J Neurosurg 2002;16:487-93.

4. Signorini DF, Andrews PJ, Jones PA, Wardlaw JM, Miller JD. Predicting survival using simple clinical variables: a case study in traumatic brain injury. J NeurolNeurosurg Psychiatry 1999;66:20-5.

5. Waxman K, Sundine MJ, Young RF. Is early prediction of outcome in severe head injury possible? Arch Surg 1991;126:1237-41; discussion 1242.

6. Choi SC, Muizelaar JP, Barnes TY, Marmarou A, Brooks DM, Young HF. Prediction tree for severely head-injured patients. J Neurosurg 1991;75:251-5.

7. Jennett B, Teasdale G, Braakman R, Minderhoud J, Heiden J, Kurze T. Prognosis of patients with severe head injury. Neurosurgery 1979;4:283-9.

8. Klauber MR, Marshall LF, Luerssen TG, Frankowski R, Tabaddor K, Eisenberg HM. Determinants of head injury mortality: importance of the low risk patient. Neurosurgery 1989;24:31-6.

9. Narayan R, Enas G, Choi S. Practical techniques for predicting outcome in severe head injury. In: Becker D, Gudeman S, editors. Textbook of head injury. Philadelphia: WB Saunders; 1989. pp. 420-25.

10. Marshall LF, Marshall SB, Klauber MR, Van Berkum Clark M, Eisenberg H, Jane JA. The diagnosis of head injury requires a classification based on computed axial tomography. J Neurotrauma 1992;9(Suppl 1):S287-92.

11. Wardlaw JM, Easton VJ, Statham P. Which CT features help predict outcome after head injury? J NeurolNeurosurg Psychiatry 2002;72:188-92; discussion 151.

12. Teasdale G, Jennett B. Assessment of coma and impaired consciousness. A practical scale. Lancet 1974;2:81-4.

13. Mukherjee KK, Sharma BS, Ramanathan SM, Khandelwal N, Kak VK. A mathematical outcome prediction model in severe head injury: a pilot study. Neurology India 2000;48:43-8.

14. Outcome Prediction Model In diffuse brain injuries:Development and evaluation: Neurology India Neurological Society Of India ; 2003;,51;345-9.

15. Nakamura N, Yamaura A, Shigemori M. Final report of the Japan neurotrauma data bank project 1998-2001: 1,002 cases of traumatic brain injury. Neurol Med Chir (Tokyo) (2006) 46:567-74. 
16. Murray GD, Teasdale GM, Braakman R. The European Brain Injury Consortium survey of head injuries.ActaNeurochir (Wien) (1999) 141:223-36.

17. Peek-AsaC.Mcarthur D, Hovda D, Kraus J . Early predictors of mortality in penetrating compared with closed brain injury. braininj 2001;15:801-10.

18. Levi L, Guilburd JN, Linn S,Feinsod M. The association between skull fracture, intracranial pathology andoutcome in pediatric head injury. Br J Neurosurg. 1991;5(6):617-625.

19. Narayan RK Enas GG et al. Chapter 21: Practical techniques for predicting outcome in severe head injury. page 420-425. IN: Becker DP Gudeman SK. Textbook of Head Injury. WB Saunders. 1989.

20. Davis RA, Cunningham PS :Prognostic factors in Severe Head Injury: 1984 Dec;159(6):597-604:PUBMED

Table No.1 Distribution of patients in two group according to age $<45 \&>45$ and their respective percentage of unfavourable outcome

\begin{tabular}{|l|l|l|l|}
\hline $\begin{array}{l}\text { Age } \\
\text { Group }\end{array}$ & $\begin{array}{l}\text { Number Of } \\
\text { Patients }\end{array}$ & $\begin{array}{l}\text { Patients with Unfavourable Outcome } \\
\text { at the end of 1 month }\end{array}$ & $\begin{array}{l}\text { Percentage } \\
\text { Unfavourable Outcome }\end{array}$ \\
\hline $\begin{array}{l}<45 \\
\text { years }\end{array}$ & 284 & 198 & 69.718 \\
\hline $\begin{array}{l}>45 \\
\text { years }\end{array}$ & 116 & 104 & 89.655 \\
\hline
\end{tabular}

Table No.2 Distribution of patient in two groups according to oculocephalic reflex and their respective percentage of unfavourable outcome -

\begin{tabular}{|l|l|l|l|l|}
\hline $\begin{array}{l}\text { Oculocephalic } \\
\text { Reflex }\end{array}$ & $\begin{array}{l}\text { Number } \\
\text { Of Patient }\end{array}$ & $\begin{array}{l}\text { Patient with predicted } \\
\text { unfavourable Outcome as } \\
\text { per NIMHANS model }{ }^{14}\end{array}$ & $\begin{array}{l}\text { Patient unfavourable } \\
\text { outcome at the end of } \\
1 \text { month }\end{array}$ & Percentage \\
\hline Absent & 172 & 164 & 154 & 93.902 \\
\hline Present & 228 & 122 & 62 & 50.82 \\
\hline
\end{tabular}

Table No.3 Distribution of patient in to groups according to Motor component GCS Nature of trauma and their respective percentage of Unfavourable outcome -

\begin{tabular}{|l|l|l|l|l|}
\hline $\begin{array}{l}\text { Motor } \\
\text { Score }\end{array}$ & $\begin{array}{l}\text { Number } \\
\text { of } \\
\text { Patients }\end{array}$ & $\begin{array}{l}\text { Patient with predicted } \\
\text { unfavourable outcome } \\
\text { as NIMHANS model } 14\end{array}$ & $\begin{array}{l}\text { Patient with } \\
\text { unfavourable } \\
\text { outcome at the end } \\
\text { of } 1 \text { month }\end{array}$ & $\begin{array}{l}\text { Percentage of } \\
\text { patient } \\
\text { unfavourable } \\
\text { outcome }\end{array}$ \\
\hline 1 & 100 & 94 & 89 & 94.681 \\
\hline 2 & 144 & 128 & 114 & 89.062 \\
\hline 3 & 90 & 62 & 43 & 69.355 \\
\hline 4 & 46 & 26 & 15 & 57.692 \\
\hline 5 & 20 & 8 & 4 & 50.0 \\
\hline
\end{tabular}


Table No.4 Distribution of patient in to groups according to Midline shift on CT scan and their respective percentage of Unfavourable outcome -

\begin{tabular}{|l|l|l|l|l|}
\hline $\begin{array}{l}\text { Midline } \\
\text { Shift }\end{array}$ & $\begin{array}{l}\text { Number } \\
\text { Of } \\
\text { Patients }\end{array}$ & $\begin{array}{l}\text { Patient predicted } \\
\text { to have poor } \\
\text { outcome as per } \\
\text { NIMHANS model }\end{array}$ & $\begin{array}{l}\text { Patient } \\
\text { unfavourable } \\
\text { outcome at the end of } \\
\text { the 1 month }\end{array}$ & $\begin{array}{l}\text { Percentage } \\
\text { patient } \\
\text { unfavourable } \\
\text { outcome }\end{array}$ \\
\hline Absent & 228 & 170 & 115 & 67.647 \\
\hline$<5 \mathrm{~mm}$ & 106 & 94 & 81 & 86.17 \\
\hline$>5 \mathrm{~mm}$ & 66 & 60 & 57 & 95.0 \\
\hline
\end{tabular}

Table-5 Showing Predictive Value for The Favourable Outcome (Senstivity) based on NIMHANS prediction model in 400 patients of diffuse brain injury in Tertiary Care Centre

\begin{tabular}{|l|l|l|l|l|}
\hline $\begin{array}{l}\text { Prediction } \\
\text { Score } \\
\text { Of more } \\
\text { than zero }\end{array}$ & $\begin{array}{l}\text { Patient With } \\
\text { favourable } \\
\text { Outcome }\end{array}$ & $\begin{array}{l}\text { Patient with } \\
\text { Unfavourable } \\
\text { Outcome }\end{array}$ & $\begin{array}{l}\text { Predictive value } \\
\text { for Favourable } \\
\text { Outcome }\end{array}$ & $\begin{array}{l}\text { Predictive Value Of } \\
\text { Favourable Outcome in } \\
\text { NIMHANS study } \\
\text { model 14 }\end{array}$ \\
\hline 114 & 95 & 19 & 83.333 & 86 \\
\hline
\end{tabular}

Table 6-_Showing Predictive Value for The Unfavourable Outcome (Specificity) based on NIMHANS prediction in 400 patients of diffuse brain injury in Tertiary Care Centre

\begin{tabular}{|l|l|l|l|l|}
\hline $\begin{array}{l}\text { Prediction } \\
\begin{array}{l}\text { Score } \\
\text { Of less than } \\
\text { zero }\end{array}\end{array}$ & $\begin{array}{l}\text { Patient With } \\
\text { favourable } \\
\text { Outcome }\end{array}$ & $\begin{array}{l}\text { Patient with } \\
\text { Unfavourable } \\
\text { Outcome }\end{array}$ & $\begin{array}{l}\text { Predictive value } \\
\text { for Unfavourable } \\
\text { Outcome }\end{array}$ & $\begin{array}{l}\text { Predictive Value Of } \\
\text { Favourable Outcome } \\
\text { in NIMHANS study } \\
\text { model }\end{array}$ \\
\hline 286 & 81 & 205 & 71.67 & 50 \\
\hline
\end{tabular}

Table 7 Showing Sensitivity and Specificity.Negative and Positive Predictive Value of Our Study Based On NIMHANS model

\begin{tabular}{|l|l|l|}
\hline Prediction score & Unfavourable Outcome & Favoureble outcome \\
\hline Less than zero & 205(True Positive) & 19(False Positive) \\
\hline More than zero & 81(False Negative) & 95(True Negative) \\
\hline
\end{tabular}

